\title{
Counting the Invisible: The Challenges and Opportunities of the SDG Indicator Framework for Statistical Capacity Development
}

\author{
Rolando Avendano, Johannes Jütting, and Manuel Kubm
}

\subsection{INTRODUCTION: WHY DATA MATTERS FOR THE 2030 AgENDA?}

Better policies demand better data. High-quality and timely data is vital for governments, civil society, the private sector, and the public to make informed decisions on inclusive growth and public well-being, to hold governments and state actors accountable, and to ensure an accurate review of the progress and implementation of the global 2030 Agenda for Sustainable Development. Today, it is widely recognised that national statistical systems play a vital role in improving the collection, provision, and dissemination of official statistics to measure the achievements towards the Sustainable Development Goals (SDGs).

Tracking progress towards the SDGs requires collecting, processing, analysing, and disseminating an unprecedented amount of data and statistics at different levels, as well as considering new data sources such as citizen-generated and geospatial data. This represents a large challenge for

R. Avendano $(\varangle)$

Asian Development Bank, Manila, Philippines

e-mail: ravendano@adb.org

J. Jütting

PARIS21, OECD, Paris, France

e-mail: Johannes.jutting@oecd.org

M. Kuhm

University of Passau, Passau, Germany

(C) The Author(s) 2021

S. Chaturvedi et al. (eds.), The Palgrave Handbook of Development

Cooperation for Achieving the 2030 Agenda,

https://doi.org/10.1007/978-3-030-57938-8_15 
all countries, in particular low-income countries and Small Island Developing States (SIDS), where resource and capacity constraints widely prevail. Although countries need strong national statistical systems to live up to the high demands of the 2030 Agenda, many do not yet seem to have the required capacities to meet the data demands of the global SDG indicator framework and its premise to leave no one behind (Organisation for Economic Co-operation and Development [OECD] 2017).

The premise to leave no one behind starts with the need that everyone be counted. Yet, at present, more than 110 low- and middle-income countries lack functional civil registration and vital statistics systems, and they under-record-or completely fail to record - vital events of specific populations (World Bank 2018). Those living in poverty are most likely to be excluded; the poorest 20 per cent of the global population account for 55 per cent of unregistered births (Development Initiatives 2017). Furthermore, only 37 countries have statistical legislation that complies with the United Nations (UN) Fundamental Principles of Official Statistics. Making the invisible visible requires strengthening national statistical systems, developing required capacities and a supporting institutional infrastructure, and implementing data disaggregation strategies that are aligned with national development plans and the 2030 Agenda.

New data sources and providers are emerging as part of the data revolution, creating opportunities and challenges for national statistical systems. Transforming big data-such as mobile phone records and search engine queries, integrating geospatial information from GPS and satellite imagery, and considering crowdsourcing opportunities through citizen-generated data-presents valid complements to official statistics, eventually leading to cost savings and the efficient allocation of already scarce resources (Ginsberg et al. 2009; Gray et al. 2016; Lämmerhirt et al. 2018; Van Halderen et al. 2016). Broadening the production, dissemination, and use of data by integrating new data sources-while ensuring the highest quality possible, and mitigating risks of misuse and privacy violations - requires a fundamentally new vision for statistical capacity development that guides concerted action by all stakeholders in the new data ecosystem.

This chapter explores the main challenges and opportunities of the global SDG indicator framework, which was adopted to track progress towards the 2030 Agenda. It analyses three core problems in statistical capacity development identified in theory and practice, and it presents possible solutions associated with the new data demands of the SDG indicator framework.

First, the overburdening of national statistical systems, as one example of social systems, can be linked to resilience theory (Adger 2000; Holling 1973). Resilience has been a core aspect of most post-2015 international frameworks, such as the 2030 Agenda, as the international community recognised the predominant importance of capacity development within people, communities, states, and institutions to reduce, prevent, anticipate, absorb, and adjust to 
different risks and stressors in the process of sustainable development (OECD 2016). Ideally, the national statistical office (NSO) is developing established data collection methods and sharing agreements with system-wide providers, as well as sufficient training and staff to compile all required official statistics to meet users' needs - we define this state as the "business-as-usual" steady state. Once a disruptive external shock, risk, or stress-such as the SDG indicator framework and its requirement to compile 232 additional indicators-is introduced, the national statistical system faces three options. First, it can move to a new steady state that meets all data demands of the SDG indicator framework-it can rise to the challenge. Second, it can show sufficient resistance and persist in its current steady state, ignoring the global monitoring requirements and remaining in its "business-as-usual" steady state. Third, it can collapse. The compilation of a 100-indicator basket is already considered the upper limit by most countries' national statistical systems, irrespective of level of income (Sustainable Development Solutions Network [SDSN] 2015), thereby putting significant weight on the latter option. However, the following analysis shows that the voluntary nature of the SDG indicator framework, a lack of overall guidance in indicator compilation, and a persistent financing gap for statistical modernisation leave national statistical systems in a transitional state between the first two options: a sufficient will to commit but an absence of capacities to rise to the challenge.

Second, the increasing number of coordination failures between donors and countries, and within national statistical systems, are connected to game theory and cost-effectiveness (Bigsten and Tengstam 2015; Bourguignon and Platteau 2015). Coordination in development assistance recognises three different dimensions (World Health Organization [WHO] 2009):

- donor coordination (focus on better coordination in the development partners group),

- aid coordination (focus on effective use of provided resources for development),

- and development coordination (focus on government leadership and coordination in national systems)

- whereas a successful intervention likely requires a blended mixture of all three dimensions. Additionally, the coordination of national statistical systems is recognised to follow four main principles: validation, participation, harmonisation, and resource maximisation (United Nations Statistics Division [UNSD] 2015). All dimensions and principles require coordination mechanisms such as regional meetings and platforms, multilateral donor funds, or common standards and guidelines to result in "development effectiveness". As disruptive technologies and new data sources break the silo between data users and producers and affect the composition of stakeholders in national statistical systems, the SDG indicator framework's data demands require reformed 
and dynamic coordination mechanisms at all dimensions and levels (global, regional, national, subnational) so as to align the multitude of incentives in the new data ecosystem.

Third, a persistent lack of funding for statistical modernisation results from the political economy of statistical capacity development, the long-term nature of evidence-based policy-making outcomes, and the absence of compelling narratives with statistical insights (Dargent et al. 2018; OECD 2017; Taylor 2016). Taking into account the political economy of statistical capacity is a considerable aspect of successful development efforts in the area of data and statistics. Generally, there are two political-economic tensions at the heart of this lack of domestic investment in statistical capacity. First, better official statistics and data result - through public policies-in the efficient allocation of national resources, and thus to considerable society-wide welfare gains. Second, better official statistics and data reveal public policy deficiencies and are used to hold government representatives accountable, and thus better data can lead to demands for political change (Taylor 2016). Therefore, weakly performing national statistical systems, and NSOs in particular, are suitable indicators for weak state capacity in general, as the incentives of public policy-making are not aligned with the broader social welfare. Moreover, the long-term nature of statistical capacity-development outcomes further weakens the incentives of government representatives to invest in national statistical systems. For example, developing the capacities within an NSO to compile an indicator on food insecurity in rural areas that details the efficient allocation of seeds and fertiliser could take months to years before rural societies receive any beneficial outcomes. Considering short electoral cycles and voter behaviour, the government would have a greater incentive to invest in ruralagricultural development right away. Consequently, empowering NSOs and aligning socio-political incentives become crucial parts of (statistical) capacitydevelopment financing. Lastly, the inability to turn statistical insights into compelling narratives - in the form of impact stories or case studies-further affects a rising distrust in numbers as well as the lack of investment in statistical modernisation.

The chapter concludes with an outlook on the role of development data in the context of "contested collaboration" and the future of development cooperation.

\subsection{The SDG Indicator Framework: Data Gaps, Capacity Constraints, and Missing Alignment Between Global Requirements and National Needs}

This section deals with the SDG indicator framework in general. It presents the main data gaps and capacity constraints faced by UN member states, which voluntarily agreed to track progress towards the 2030 Agenda. As supporting evidence for the missing alignment between global requirements and national 
needs, the section presents results from a survey conducted in 2018 by the Partnership in Statistics for Development in the 21st Century (PARIS21) and the High-Level Group for Partnership, Coordination and Capacity-Building for statistics for the 2030 Agenda (HLG-PCCB).

\subsubsection{Pevsistent Sustainable Development Data Gaps}

The SDG data framework, adopted on a voluntary basis in 2017 , consists of 232 global indicators that build on the national and regional data of UN member states. National statistical systems are the main supporting structure for the compilation of the SDG indicators. The framework and its unprecedented ambition for global results-measurement towards a commonly defined global development agenda created a number of challenges for national statistical systems and the international statistical community alike.

An initial assessment of data availability indicates that the data revolution has not yet reached all countries. A recent assessment revealed that, on average, data for only 40 (20 per cent) of the adopted global SDG indicators are currently available, and another 47 global indicators ( 23 per cent) are considered "feasible" (i.e. data sources are available and the indicators could be compiled; United Nations Department of Economic and Social Affairs 2018). In other words, almost 60 per cent of SDG indicators lack most of the required data, are unavailable, or are methodologically undefined by the international statistical community. However, significant improvements in Tier I indicators (defined as conceptually clear, methodologically established, and regularly produced by at least 50 per cent of countries) are being achieved. In 2019, 101 SDG indicators were classified as Tier I, up from 82 indicators in 2017 (UNSD 2019).

On top of increasing demand, the 2030 Agenda requires data that is at least disaggregated by income, sex and gender, geography, age, and disability. Geographic disaggregation helps, for instance, in understanding the distributional impacts of poverty reduction policies, while gender-disaggregated data sheds light on the discrimination, exclusion, and marginalisation of social subgroups. However, several disaggregation dimensions lack benchmark definitions, standards, or classification criteria because concepts such as urban/rural or poor/non-poor concepts are not harmonised across countries. Likewise, most demographic and health surveys lack definitions for gender identity and disability, and they fail to adequately represent young (5-14 years) and old (over 49 years) age groups (OECD 2018). Allocated resources to data disaggregation are also scant: Only 13 per cent of countries worldwide have a dedicated budget for gender statistics. The evidence and modest progress made since the adoption of the SDG indicator framework suggests that national statistical systems are not yet fit to meet the data (and disaggregation) demands of the 2030 Agenda. 


\subsubsection{Capacity Constraints and Missing Alignment Between Global Requirements and National Needs}

Statistical capacity can be defined as "the ability of a country's national statistical system, its organisations and individuals to collect, produce, analyse and disseminate high-quality and reliable statistics and data to meet users' needs" (Partnership in Statistics for Development in the 2lst Century [PARIS21] 2018a). This definition stresses different levels (individual, organisational, and systemic) and the importance of considering a virtuous data life cycle in capacity-development efforts. It highlights a country-led, demand-driven, and long-term approach, in contrast to traditional supply-driven and external technical capacity-building efforts.

In 2017, PARIS21 and the HLG-PCCB designed a survey that aims to provide a better understanding of the current state of capacity-development efforts across national statistical systems, and the challenges, priorities, and plans NSOs have in view of SDG indicator framework implementation. This survey provides useful insights on untapped areas of capacity development, including individual non-technical skills, organisational practices, coordination between national agencies, and the mainstreaming of SDGs in national policies and reporting mechanisms. In 2017, the questionnaire was distributed to 193 UN member states and 2 non-members, of which 96 submitted a reply (around a 50 per cent response rate). The full results are published by PARIS2l (2018b).

The survey results indicate some regional discrepancies in the three most urgent SDG monitoring needs (see Table 15.1). Countries in Asia and the Pacific tend to prioritise indicators related to poverty, health, and well-being, whereas countries in Africa prioritise indicators related to poverty, food security, and water and sanitation. However, all regions stressed indicators related to poverty and its dimensions as a Top l capacity-development priority. A glance at the data by country income groups (low-income, lower-middleincome, upper-middle-income, and high-income) reveals a more nuanced picture of the most urgent SDG monitoring needs. Lower-middle-income countries tend to prioritise poverty indicators within their Top 3 priorities, whereas high-income countries express more interest in food security, gender equality, and education in their SDG indicator capacity-development efforts. Respecting expressed capacity-development needs against the backdrop of the SDG indicator framework in statistical capacity-development programmes offers great potential to produce the most sustainable results in the future.

The need for tailored SDG indicator production strategies becomes even more apparent when comparing regional disaggregation priorities (see Fig. 15.1). Disaggregation by income and geographical location is more important in Africa than anywhere else in the world. Disaggregation by migrant status needs immediate support in Asia and the Pacific, whereas disaggregation by disability is more important in Latin American and the Caribbean. These results illustrate that regional priorities vis-à-vis the 2030 
Table 15.1 Survey results on regional SDG indicator prioritisation

\begin{tabular}{|c|c|c|c|}
\hline $\begin{array}{c}\text { Geographic } \\
\text { region/Income group }\end{array}$ & Top 1 & Top 2 & Top 3 \\
\hline Global & $\begin{array}{c}\text { 1.1.1: Proportion of population below the } \\
\text { international poverty line } \\
\text { (disaggregated) }\end{array}$ & $\begin{array}{l}\text { 2.1.2: Prevalence of moderate or severe } \\
\text { food insecurity in the population }\end{array}$ & $\begin{array}{l}\text { 1.2.2: Proportion of population living in } \\
\text { poverty in all its dimensions }\end{array}$ \\
\hline Africa & $\begin{array}{c}\text { 1.1.1: Proportion of population below the } \\
\text { international poverty line } \\
\text { (disaggregated) }\end{array}$ & $\begin{array}{l}\text { 2.1.2: Prevalence of moderate or severe } \\
\text { food insecurity in the population }\end{array}$ & $\begin{array}{l}\text { 6.5.1: Degree of integrated water } \\
\text { resources management implementation }\end{array}$ \\
\hline Asia and Pacific & $\begin{array}{c}\text { 1.1.1: Proportion of population below the } \\
\text { international poverty line } \\
\text { (disaggregated) }\end{array}$ & $\begin{array}{l}\text { 1.2.1: Proportion of population living } \\
\text { below the national poverty line } \\
\text { (disaggregated) }\end{array}$ & 3.2.1: Under-5 mortality rate \\
\hline Eastern Europe & $\begin{array}{l}\text { 1.2.2: Proportion of population living in } \\
\text { poverty in all its dimensions }\end{array}$ & 2.c.1: Indicator of food price anomalies & None \\
\hline $\begin{array}{l}\text { Latin America and } \\
\text { Caribbean }\end{array}$ & $\begin{array}{l}\text { 1.3.1: Proportion of population covered } \\
\text { by social protection (disaggregated) }\end{array}$ & $\begin{array}{l}\text { 2.1.2: Prevalence of moderate or severe } \\
\text { food insecurity in the population }\end{array}$ & None \\
\hline $\begin{array}{l}\text { Western Europe and } \\
\text { Others }\end{array}$ & None & $\begin{array}{l}\text { 5.2.2: Proportion of female population } \\
\text { subjected to sexual violence } \\
\text { (disaggregated) }\end{array}$ & $\begin{array}{l}\text { 2.2.2: Prevalence of malnutrition among } \\
\text { children under } 5 \text { years (disaggregated) }\end{array}$ \\
\hline Low-Income & None & None & $\begin{array}{l}\text { 6.5.1: Degree of integrated water } \\
\text { resources management implementation }\end{array}$ \\
\hline Lower-Middle-Income & $\begin{array}{c}\text { 1.1.1: Proportion of population below the } \\
\text { international poverty line } \\
\text { (disaggregated) }\end{array}$ & $\begin{array}{l}\text { 1.2.1: Proportion of population living } \\
\text { below the national poverty line } \\
\text { (disaggregated) }\end{array}$ & $\begin{array}{l}\text { 1.2.2: Proportion of population living in } \\
\text { poverty in all its dimensions }\end{array}$ \\
\hline Upper-Middle-Income & $\begin{array}{l}\text { 1.2.2: Proportion of population living in } \\
\text { poverty in all its dimensions }\end{array}$ & $\begin{array}{l}\text { 2.1.2: Prevalence of moderate or severe } \\
\text { food insecurity in the population }\end{array}$ & $\begin{array}{l}\text { 6.2.1: Proportion of population using } \\
\text { sanitation services }\end{array}$ \\
\hline High-Income & $\begin{array}{l}\text { 2.1.2: Prevalence of moderate or severe } \\
\text { food insecurity in the population }\end{array}$ & $\begin{array}{l}\text { 5.2.2: Proportion of female population } \\
\text { subjected to sexual violence } \\
\text { (disaggregated) }\end{array}$ & $\begin{array}{l}\text { 4.c.1: Proportion of teachers in primary } \\
\text { and secondary education having } \\
\text { received minimum training }\end{array}$ \\
\hline
\end{tabular}

Question 10: Considering your national priorities, what are the Top 3 Sustainable Development Goal indicators (please select only Tier II and I) that require immediate capacity building in your National Statistical Office?

Note "None" indicates that no SDG indicator was selected at least twice by two different countries in the same region/income group. Shade intensity represents the percentage of countries in the respective region/income group that selected the indicator (darker shade corresponds to higher percentage)

Source PARIS21 (2018b)



Fig. 15.1 Survey results on regional disaggregation requirements. Question 12: Please indicate what types of data disaggregation require the most immediate support (Source PARIS21 2018b) 
Agenda are heterogeneous. Designing country-driven, localised SDG monitoring and disaggregation strategies in statistical capacity-development efforts will be an effective solution, given the immediate resource and capacity constraints.

\subsection{SDG INDICATOR FRAMEWORK IMPLEMENTATION: Main Challenges and Possible Solutions}

This section outlines the three main challenges of the SDG indicator framework for national statistical systems, overburdening, coordination failures, and the lack of funding, and it presents possible solutions. Conclusively, Sect. 15.4 offers an outlook on the role of data in the future of development cooperation.

\subsubsection{Lessen Overburdening of National Statistical Systems}

The 2030 Agenda acknowledges the potential for reporting overburden and recommends that national statistical systems build on existing reporting mechanisms (WHO 2019). With follow-up and review processes being voluntary and country-led, several approaches are proposed to tackle the overburdening of national statistical systems. First, the statistical community could define a reduced set of indicators, thereby respecting global and key regional priorities. A 100-indicator basket is already considered to be an upper limit by most countries, irrespective of levels of income (SDSN 2015). Multi-purpose indicators could also be introduced to track progress towards different cross-cutting targets. Second, localised indicator frameworks incorporating "complementary indicators" that countries have chosen themselves for measuring particular national and/or regional concerns could be a valuable tool to reduce reporting burden. Most UN regional commissions are well-equipped to design illustrative national indicator frameworks to align regional and international monitoring needs. Third, designing new outreach strategies and incentives for collaboration with new actors is essential. Established platforms such as the World Business Council on Sustainable Development could be used to engage with the business community for designing complementary key performance indicators. Fourth, innovative planning tools can help in tracking reporting burden and presenting proper costing estimates for leveraging domestic and external financial resources (see Box 15.1). 


\section{Box 15.1 Improving planning and SDG readiness through ADAPT}

The Advanced Data Planning Tool (ADAPT), developed by PARIS21, is an innovative web-based planning tool for NSOs to adapt their data production to the priority data needs of policy-makers. ADAPT is a consultative tool that brings data stakeholders together and defines the measurement context for relevant development plans in global and national contexts. ADAPT can be used for monitoring and analysing data gaps against the SDG indicator framework.

Currently, ADAPT is being used by national agencies and international partners-notably the United Nations Statistics Division-in 21 countries worldwide. The new version of ADAPT features a costing module that provides statistical staff and policy-makers with detailed estimates of the required financial resources to close critical data gaps and meet national data needs. ${ }^{1}$

\subsubsection{Avoiding Coordination Failures}

A lack of coordination between beneficiaries, development partners, and donors funding statistical capacity development has led to duplication and unsustainable intervention results, as parties do not necessarily work together or strategies are poorly aligned with national data needs. Additionally, the new data ecosystem and its multitude of emerging providers requires innovative coordination mechanisms and strategies to foster effective data-sharing, integration, and quality assurance in the process.

Linked to the challenge of using national data for international monitoring is the need to better align national and international efforts to strengthen statistical capacity (PARIS21 2013). A coherent, inclusive, feasible, and politically backed national statistical plan can guide progress towards strengthened statistical capacity across the entire national statistical system. In 2018, 129 countries were implementing a national statistical plan-an increase of 26 per cent from 102 countries in 2017. Capacity-development strategies should emerge from an open and collaborative dialogue by local representatives from civil society and the political sphere as well as external partners and private stakeholders about their shared objectives and interests in addition to their respective contributions to the common goal.

Integrating emerging data providers into national statistical systems demands strengthening soft skills such as leadership and communication as well as establishing data partnerships and coordination mechanisms between all stakeholders to avoid critical failures and reduce risks (see Box 15.2). Integrative consultation platforms and processes for defining a set of nationally relevant indicators for data collection, open data principles to foster data collaboration efforts, and guidelines for leveraging innovative complementarities between traditional and new data sources (e.g. big data, citizen-generated data), as provided by private sector companies, will reduce costs and minimise levels of confusion related to data discrepancies. Furthermore, extended 
quality assurance frameworks will be needed to ensure the appropriate integration of new data sources while respecting confidentiality and privacy rights. Ultimately, successful coordination and collaboration in the new data ecosystem depend on fostering political will and establishing trust between all involved stakeholders.

\section{Box 15.2 Effects of SDG data demands in Small Island Developing States} In the era of SDGs, SIDS face enormous statistical challenges due to the increased scope, depth, and level of detail of data needs for monitoring progress in achieving the SDGs. This was recognised early on by SIDS. Thus, in the cases of both the Caribbean and Pacific regions, it was agreed to produce a core set of SDG indicators relevant to their respective regions while taking into consideration the constraints of their overstretched national statistical systems (Caribbean Community 2018). It is important to note that SIDS national statistical systems vary considerably in terms of the size of NSOs, the available resources for statistics, technical capacity, institutional environments that support statistical work, political support, and data availability. Their capacity and readiness to address SDG data needs will largely depend on these factors as well as the extent to which the SDGs align with their national development policies and frameworks. Common SIDS challenges identified that relate to SDGs include, among others, funding insecurity, constraints in human resources, weak statistical systems, and missing alignment between global data collection requirements and existing national concerns.

SIDS would need considerable funding to improve capacity and modernise national statistical systems. This would enable them to undertake the full range of statistical activities required to produce the data for monitoring the SDGs. As SIDS represent around 1 per cent of the global population, the unusually high per capita expenses for statistical activities preclude governments from allocating the necessary budget for statistics, which often results in the need for external financial support. However, dependence on external funding does not translate into a higher level of commitment to SIDS. In fact, external funding commitments to SIDS remain at a low level, with only about $\$ 33$ million-or 5 per cent of total global commitments-for the period 2014-2016 (PARIS21 2018c). Only eight SIDS received funding of \$1 million or over during the same period, which is unlikely to be sufficient in producing sustainable statistical capacity-development outcomes (PARIS21 2019b).

Source Authors

\subsubsection{Overcoming Funding Gap}

Investing in national statistical systems needs to become a strategic priority for low- and lower-middle-income countries as well as providers of development cooperation (OECD 2017). The total estimated cost for 144 low- and middleincome countries to produce data for the SDG indicators (Tiers 1 and 2) is estimated at $\$ 2.8$ to $\$ 3.0$ billion per year until 2030 (Global Partnership for 
Sustainable Development Data 2016), while the cost for the implementation of all Cape Town Global Action Plan objectives rises to $\$ 5.6$ billion annually. Assuming an ambitious scenario of domestic resource mobilisation in lowand middle-income countries, closing the funding gap for SDG data demands and Cape Town Global Action Plan implementation requires doubling current external support for statistics-from 0.33 per cent (around $\$ 600$ million) to 0.7 per cent per year (around $\$ 1.3$ billion; PARIS21 2019a).

However, the level of financing for development is only part of the story. Simply increasing the amount of investment for statistical capacitydevelopment efforts is unlikely to bring results without revising the delivery mechanisms behind them (PARIS21 2018c). An emerging consensus among development partners, agencies, and countries calls for more concerted action and coordination in the provision of capacity and technical support in the sector. Integrating new and better data sources in official statistics, improving the quality of financing for statistics, aligning country priorities for data with global monitoring demands, and creating compacts for country-led development data initiatives offer a promising vision for sustainable statistical capacity development in low- and lower-middle-income countries. The model of establishing a global partnership for managing financial resources for data could be extended to other areas. For example, to optimise capacity-development planning and the comparative advantages of capacitydevelopment programmes among providers, alignment through established approaches-including strategic frameworks such as the National Strategies for the Development of Statistics, and planning tools such as ADAPT-will continue to ensure a strong basis for coordination (PARIS2l 2019b).

\subsection{The Changing Role of Data and Statistics in Development}

Development cooperation paradigms are continually shifting and evolving because of the mismatch between predominant ideologies and accumulated experiences (Innis 1951). As development paradigms shift, so does the role of development data. The post-war era focussed on economic statistics and how they informed trade integration processes before moving on to social statistics in the 1970s and 1980s, which spawned various household survey initiatives. Advances in digital technologies in the 1990s facilitated the transition towards regular data-reporting systems to design and inform policy planning. Additionally, it entailed the introduction of the first data dissemination standards, thereby strengthening the international statistical community. The ambitious results-measurement frameworks of the Millennium Development Goals and the SDGs in the 2000s created an unprecedented imperative for more and better data on the national levels for informing development plans and Poverty Reduction Strategy Papers for achieving the 2030 Agenda. The subsequent sections present three emerging proposals for strengthening the role of data 
in development, created in an effort to rise to the challenges of the SDG indicator framework: triangular cooperation in statistical capacity development, a global financing facility for development data, and the power of humanising data through compelling stories.

\subsubsection{Triangular Cooperation in Data and Statistics}

The 2030 Agenda and its SDGs are broadening development efforts across the entirety of governments and societies worldwide while further diversifying the development cooperation landscape through the integration of new actors and partners. As a result, the management of development efforts and partner collaboration at the country level is fundamentally changed. These changes, in turn, affect the way government institutions organise themselves to manage development cooperation by putting specific coordination mechanisms and structures in place.

The engagement of new development partners needs to be effective and meaningful. Multi-stakeholder dialogues and inclusive consultations are needed to harness the full potential for building trust, the effective use of public resources, and the meaningful engagement of emerging donors and the private sector in development cooperation towards the 2030 Agenda. Furthermore, mutual accountability mechanisms between - and results-measurement frameworks of - the stakeholders involved need to be in place to manage the increasingly diverse landscape of partners engaged in statistical capacity development.

New forms of development cooperation in data and statistics are acknowledged and growing in importance. Triangular and South-South cooperation are considered an expression of multiple stakeholders and their desire to engage in practical and effective forms of cooperation in capacity-development efforts (Federal Ministry for Economic Cooperation and Development 2013). Typically, triangular cooperation in data and statistics involves the joint planning, financing, and implementation of capacity-development projects by an established Development Assistance Committee (DAC) donor, an emerging economy, and a beneficiary country. However, other forms of triangular cooperation in data and statistics exist as well. Typically, the collaboration involves a beneficiary NSO, an NSO from a DAC member country, and a funding agency. Rather than a new cooperation arrangement, triangular cooperation is considered as an additional instrument to foster mutual learning and knowledge exchange between all involved parties. PARIS2l has undertaken this collaborative approach with different development partners. The partnership between Statistics Canada, Global Affairs Canada, and PARIS21 has allowed for prioritising the beneficiaries' perspectives and aligning support with national priorities in order to identify synergies with Canada's overall development cooperation strategy. Similarly, the collaboration between the Department for International Development, the Office of National Statistics, and PARIS2 1 aims at identifying and leveraging UK policy experts to 
participate in development cooperation projects along the lines of international development priority areas. The results of these approaches are promising and should be further developed with other development providers.

\subsubsection{Sustainable Financing for Development Data}

Investing in data brings returns. Yet, national statistical systems in low- and lower-middle-income countries still face systematic underfunding and critical resource constraints. Quantitatively, the funding landscape for development data is confronting regional concentration and a high share of loan financing, posing challenges for project planning and implementation (PARIS2l 2019b). Additionally, closing the funding gap for SDG reporting will require substantial resource mobilisation by leveraging domestic public finance or new pooled funding mechanisms. Qualitatively, development data is experiencing a lack of political awareness and low visibility, which has resulted from an insufficient understanding of data analysis and use (PARIS21 2019a). Additionally, the minimal harmonisation of support due to significant fragmentation, the poor alignment of external support to country systems and strategies, and poor sustainability and predictability prevent support from becoming effective. The possibility for data to be used as both a decision tool by public servants and an accountability tool by the public to hold policy-makers accountable weakens the incentives of government representatives to invest in better data, thus further limiting the public finance window.

Closing the development data funding gap and fulfilling these principles requires new mechanisms and instruments in order to improve donor coordination and the effectiveness of investments in statistical capacity development. The creation of a global financing facility or a global fund for sustainable development data could raise the political demand for data, improve alignment with national priorities, promote development partner coordination, and speed up access to finance at scale. Global funds have a greater capacity to address the challenges of funding statistical capacity development than other financial mechanisms, such as Multi-Donor Trust Funds, which are useful tools for emergency assistance (PARIS2l 2019a). If designed properly, such a facility could match funding for national capacities with existent countryowned investment plans, and at the same time seed money for data innovation and new partnerships.

The concept of "aid as catalyst", which introduces public official development assistance as a leveraging force for private and further public resource mobilisation, is indeed already being observed in the data context. The prominence of emerging donors and philanthropic organisations in the data sector is noticeable. Between 2013 and 2015, nearly \$574 million (2.4 per cent of all philanthropic support to development) can be linked to projects with a strong data and statistics component, in particular in medical and agricultural research (PARIS2l 2018c). Current discussions on multilateral financing, in 
particular the World Bank International Development Association replenishment in 2019, aim at bringing additional financial resources to underfunded sectors, such as data and statistics. Current discussions could include the firstever horizontal policy commitment for development data, which could serve as a catalyser for other actors to attract financial resources from the private and public sectors alike in the future.

However, there are still barriers preventing the public and private consolidation of financial resources for statistical capacity development. Development partners could rethink their role in the sector for attracting other forms of financial resources while providing "seed" financing for key areas of statistical development.

\subsubsection{The Power of Stories-Humanising Data}

Compelling narratives and reasons to invest in data need to be communicated to convince development partners to increase funding and efforts. For this purpose, stories of impact have to be well-documented and shared with the widest audience possible. In the past, data has proven to be able to save lives: For example, in the health sector, better data on maternal deaths and their causes during childbirth ensured that subsequent mothers did not have to die the same way during labour (WHO 2018). Additionally, data has proven to be able to improve lives: For example, in the financial sector, civil registration is a prerequisite to be eligible for access to credit and cash grants. The communication of new narratives wrapped in engaging case studies illustrating how SDG monitoring has saved and improved lives will be a means to an end of securing more and better funding for statistics and data.

Conclusively, the role of data in development presents one area of "contested collaboration" in development cooperation. First, global actors and, in particular, data partnerships contest existing institutions by elaborating new and flexible approaches to statistical capacity development (regime creation) and creating new mechanisms and instruments for development data financing (regime shifting). Second, the role of data in development fosters new and existing forms of collaboration through multi-stakeholder partnerships and new forms of cooperation (e.g. triangular), and by achieving cohesion between collective capacity-development efforts and national priorities (e.g. National Strategies for the Development of Statistics, "localised" SDG indicator frameworks). To attain these objectives, a revised approach to capacity development is needed that recognises elements such as leadership, management, and communication skills as effective vehicles for strengthening data systems. With a revised approach, development data can be a powerful driver and essential part in a new framing of data for development cooperation. 


\subsection{CONCLUSION}

Providing an accurate review of the progress and implementation of the 2030 Agenda for Sustainable Development requires taking advantage of the "data revolution". Although there are opportunities to take advantage of, national statistical systems in developing countries still lack the necessary capacities to rise to the challenge and require more fundamental forms of support.

National statistical systems need to be modernised and strengthened significantly to meet the requirement for the sheer amount of data demanded by the global SDG indicator framework. The issues faced by statistical systems extend to three predominant themes: overburdening in data reporting, coordination failures in data partnerships, and inadequate funding.

Sustainable development strategies that are based on the global SDG indicator framework and incorporate key economic, social, political, and environmental aspects must be locally owned. Locally defined indicator frameworks and a reduced set of global indicators aligned with national and/or regional priorities present one opportunity to avoid the overburdening of national statistical capacities. Fostering collaboration platforms and political will-by strengthening trust and incentives in statistical capacity development-will be a prerequisite to avoid critical coordination failures in newly emerging multi-stakeholder data partnerships. Closing the development data funding gap requires a revised perspective on mechanisms and instruments so that they improve coordination and become more effective. Current discussions on a global financing facility for sustainable development data are leading in this direction.

Lastly, development is about human experiences. Humanising statistical capacity-development efforts by using compelling narratives and stories of impact about the power of data to save and improve lives will be a means to an end towards securing the necessary resources to ensure an accurate and quantifiable review of the progress and implementation of the global 2030 Agenda for Sustainable Development. Better policies demand better data, and better data demands better stories.

\section{Note}

1. For more information on ADAPT, please visit https://adapt.paris21.org/.

\section{REFERENCES}

Adger, W. N. (2000). Social and ecological resilience: Are they related? Progress in Human Geography, 24(3), 347-364.

Bigsten, A., \& Tengstam, S. (2015). International cooperation and the effectiveness of aid. World Development, 69, 75-85.

Bourguignon, F., \& Platteau, J. (2015). The hard challenge of aid coordination. World Development, 69, 86-97. 
Caribbean Community. (2018). CARICOM core indicators for the Sustainable Development Goals (SDGs): Assessment of data availability in member states and associate members. Georgetown, Guyana: Caribbean Community Secretariat.

Dargent, E., Lotta, G., Mejía-Guerra, J. A., \& Moncada, G. (2018). Who wants to know? The political economy of statistical capacity in Latin America. Washington, DC: Inter-American Development Bank.

Development Initiatives. (2017). P20 Initiative: Baseline report. http://devinit.org/ wp-content/uploads/2017/03/P20-Initiative-baseline-report.pdf.

Federal Ministry for Economic Cooperation and Development. (2013). Triangular cooperation in German development cooperation. Bonn: Author.

Ginsberg, J., Mohebbi, M. H., Patel, R. S., Brammer, L., Smolinski, M. S., \& Brilliant, L. (2009). Detecting influenza epidemics using search engine query data. Nature, 457, 1012-1014.

Global Partnership for Sustainable Development Data. (2016). The state of development data funding. https://opendatawatch.com/wp-content/uploads/2016/09/develo pment-data-funding-2016.pdf.

Gray, J., Lämmerhirt, D., \& Bounegru, L. (2016). Changing what counts: How can citizen-generated and civil society data be used as an advocacy tool to change official data collection? http://civicus.org/thedatashift/wp-content/uploads/2016/ 03/changing-what-counts-2.pdf.

Holling, C. S. (1973). Resilience and stability of ecological systems. Annual Review of Ecology and Systematics, 4, 1-23.

Innis, H. A. (1951). Industrialism and cultural values. American Economic Review, 41(2), 201-209.

Lämmerhirt, D., Gray, J., Venturini, T., \& Meunie, A. (2018). Advancing sustainability together? Citizen-generated data and the Sustainable Development Goals. http://www.data4sdgs.org/sites/default/files/services_files/Advancing\%20S ustainability\%20Together\%20CGD\%20Report_0.pdf.

OECD (Organisation for Economic Co-operation and Development). (2016). Resilience systems analysis: Learning and recommendations report. http://www.oecd. org/dac/conflict-fragility-resilience/docs/SwedenLearning_Recommendationsrep ort.pdf.

OECD. (2017). Development co-operation report 2017: Data for development. Paris: OECD Publishing.

OECD. (2018). Development co-operation report 2018: Joining forces to leave no one behind. Paris: OECD Publishing.

PARIS21 (Partnership in Statistics for Development in the 21st Century). (2013). Strengthening national statistical systems to monitor global goals. https://www.oecd. org/dac/POST-2015\%20P21.pdf.

PARIS21. (2018a). Proposing a framework for capacity development 4.0. https://par is21.org/sites/default/files/inline-files/CD4.0-Framework_final.pdf.

PARIS21. (2018b). Survey results: New approaches to capacity development and future priorities. https://paris21.org/capacity-development-40/cd40-survey.

PARIS21. (2018c). Partner report on support to statistics: PRESS 2018. https://par is21.org/sites/default/files/inline-files/PRESS2018_BAT_web_v2.pdf.

PARIS21. (2019a). Mobilising data for the SDGs (PARIS21 Discussion Paper No. 15). Paris: Author. 
PARIS21. (2019b). Statistical capacity development outlook 2019. http://statisticalc apacitymonitor.org/pdf/Statistical\%20Capacity\%20Development $\% 20$ Outlook\%202 019.pdf.

SDSN (Sustainable Development Solutions Network). (2015). Developing indicators for the Sustainable Development Goals: Reflections on the work of the IAEG-SDGs. https://www.unsdsn.org/news/2015/06/23/reflections-on-the-iaeg-sdgs.

Taylor, M. (2016). The political economy of statistical capacity. Washington, DC: InterAmerican Development Bank.

United Nations Department of Economic and Social Affairs. (2018). The Sustainable Development Goals Report 2018. New York, NY: Author.

UNSD (United Nations Statistics Division). (2015). Coordination national statistical systems, global, regional. https://unstats.un.org/unsd/nationalaccount/workshops/ 2016/Caribbean/Session_1_Dominica.pptx.

UNSD. (2019). Tier classification for global SDG indicators. https://unstats.un.org/ sdgs/files/Tier\%20Classification\%20of\%20SDG\%20Indicators_13\%20February\%202 019_web.pdf.

Van Halderen, G., Minchin, S., Brady, M., \& Scott, G. (2016). Integrating statistical and geospatial information, cultures and professions: International developments and Australian experience. Statistical Journal of the IAOS, 32(4), 457-470.

WHO (World Health Organization). (2009). Review of coordination mechanisms for development cooperation in Tajikistan. http://www.euro.who.int/_data/assets/ pdf_file/0013/106411/E93771.pdf.

WHO. (2018). Maternal mortality. https://www.who.int/gho/maternal_health/ mortality/maternal_mortality_text/en/.

WHO. (2019). How is progress towards SDGs measured and reported on? http:// www.euro.who.int/en/health-topics/health-policy/sustainable-development-goals/ q-and-a-health-and-the-sustainable-development-goals/6.-how-is-progress-towardsthe-sdgs-measured-and-reported-on.

World Bank. (2018). Global civil registration and vital statistics. https://www.worldb ank.org/en/topic/health/brief/global-civil-registration-and-vital-statistics.

Open Access This chapter is licensed under the terms of the Creative Commons Attribution 4.0 International License (http://creativecommons.org/licenses/by/4.0/), which permits use, sharing, adaptation, distribution and reproduction in any medium or format, as long as you give appropriate credit to the original author(s) and the source, provide a link to the Creative Commons license and indicate if changes were made.

The images or other third party material in this chapter are included in the chapter's Creative Commons license, unless indicated otherwise in a credit line to the material. If material is not included in the chapter's Creative Commons license and your intended use is not permitted by statutory regulation or exceeds the permitted use, you will need to obtain permission directly from the copyright holder.

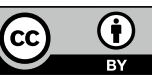

